RESEARCH REPORT

\title{
PREVALENCE OF DEVELOPING IPHONE ELBOW IN UNDERGRADUATE STUDENTS USING SMARTPHONE
}

\begin{abstract}
\section{OBJECTIVE}

The study is intended to identify the prevalence of developing iphone Elbow in young undergraduate physical therapy students using Smartphone.

\section{STUDY DESIGN}

Study design is a cross-sectional observational survey of DPT students METHODOLOGY

206 adolescent students aged 15-28 years, using smart phones frequently or handheld gadgets were asked to fill a questionnaire to analyze the frequency of using smart phones and the activities performed on the devices. The intensity of pain associated with Smartphone usage was identified using VAS scale. COZEN test was performed for diagnosis of Epicondylitis.

RESULT

Results revealed that the frequency of Smartphone usage is higher between 20 and 21 years of age. Interestingly, the results obtained in this study shows that $67.5 \%$ students make calls and $60.7 \%$ use video chatting while message reading was found to be $43.7 \%$ and sending message is $39.8 \%$. Putting down notes and task orientation is $40 \%$. Comparatively the typing activities of muscles were found to be high. On the VAS scale $35 \%$ of participants sometimes feel pain and $10.2 \%$ often complain of pain with uneasiness, demonstrating decreased muscular strength. However, regarding posture, youngsters who use sitting posture are $39.3 \%$ and those who prefer supine lying posture are $32 \%$ while those who never use Smartphone in prone lying are $46.1 \%$ and those who rarely use their device in prone are $25.7 \%$. Cozen test was found to be negative in $80.6 \%$ and only $19.4 \%$ test results turned out to be positive.
\end{abstract}

\section{KEYWORDS}

Tennis Elbow, lateral epicodylitis, epicondylalgia, smart phones, MSK injuries and youngsters, overuse injuries.

\author{
Hassan Abbas Rizvi \\ Associate Professor, Principal \\ Liaquat National School of \\ Physical Therapy \\ Liaquat National Hospital \\ Hassan.abbas@Inh.edu.pk

\section{Hafiza Humaira Anjum} \\ DPT Student \\ Ziauddin College of Physical \\ Therapy \\ Ziauddin University

\section{Sidra Salahuddin} \\ DPT Student \\ Ziauddin College of Physical \\ Therapy \\ Ziauddin University

\section{Saba Khan} \\ DPT Student \\ Ziauddin College of Physical \\ Therapy \\ Ziauddin University
}

[Rizvi HA, Anjum HH, Salahuddin S Khan S. Prevalence of developing iphone elbow in undergraduate students using smartphone. Pak. j. rehabil. 2016;5(1):18-24] 


\section{INTRODUCTION}

Smartphone is globally used by more than 4 billion people' due to the impressive and user friendly features. There are about $90 \%$ youngsters carrying their phones in their arms without the discrimination of time, day or place ${ }^{2-3}$. Hence, it is leading to painful conditions in the upper extremity, which researchers have coined in a term as iPhone Elbow $(\mathrm{IP})^{4}$. It causes inflammation of tendon, resistance in movements, repetitive motion and stress ${ }^{4}$. In the late $19^{\text {th }}$ century IP was named as 'Lawn Tennis Arm ${ }^{5}$ due to the association of lateral elbow pain with lawn tennis. The most common complaint of pain, tenderness, tightness at lateral aspect of elbow is clearly identified during extension. Decrease in muscle strength, radiating pain in forearm and activities of daily living ${ }^{5}$ are the main complaints

Researchers reveal that this degenerative disorder is mostly untraceable, misunderstood and often being controversial as some literatures claim the prefix "itis" is the misnomer. Hence the sensitivity of pain is due to Tendinopathy because it is no longer considered as an inflammatory condition'.

A few histological studies have been conducted and were ended with conclusion that there is no inflammation in extensor tendon origin. However, in the year $1910^{7-8}$ a study was conducted to further investigate the condition in which researchers documented periostitis of the humeral epicondyle as the main cause. Tendinosis developed due to degenerative changes were also reported as a source of pain ${ }^{9,10}$.

Although it comprises some degrees of disruption of extensor muscle tendons, originating from lateral epicondyle of elbow. In a number of studies authors have been related the presentation of injury to different sports specially Tennis Sports. However it is a fact that it is more common in non racquet players and in working population, only $5-10 \%$ of patient who appear with symptoms were actually playing Tennis"1". And in most advanced researches it is more likely that youngsters use hand held gadgets for extended duration which means sustained holding and gripping the piece of object in unsupported position that is believe to be the chief cause of IP'2.

Frequent Complains such as muscular pain, abnormal posture, hunched shoulder, twisted hand, claw wrist and angulations of neck were documented ${ }^{12}$. All these problems occur as people harness themselves to these portable devices pushing their bodies to increased risk of musculoskeletal injuries ${ }^{13}$. Moreover several other problems related to head and neck have also been documented ${ }^{12-13}$.
Now-a-days symptoms of degenerative diseases such as IP have begun to appear in people between 15 to 28 years of age. Most common purposes of using devices that have been also considered as risk factors are social entertaining websites, news, free mobile applications, games, MS office, emails; in a few words to avail convenience of staying connected anywhere any time. It can also be associated with any other activities required for repetitive movements for e.g. bent elbow, extended and deviated wrist in writing and brushing, typing and continuous use of small tools. Growing number of cases related to the use of hand held devices such as Tablet and smart phones have been reported by medical practitioner, because of attaining unstable posture while keeping muscles and joints under stress. This is not only affecting a single joint or muscle but whole body so the user also perceives referred pain from other muscles. Some of the positions like gripping while keeping the elbow and wrist flexed or extended at varying angles for sustained duration leading to lateral epicondylalgia in youngsters ${ }^{13}$.

Previously studies related to Tennis Elbow have been conducted on selected sports and occupational population in association with forceful task, repetitive activities or combination of both ${ }^{14}$. The aim of this study is to estimate the prevalence of IP in young age group. Prevalence of epicondylalgia that leads to tendonitis is same that is constant contraction of muscle but in different strenuous activity for e.g. to clutch the gadget, twiddling, dragging, flicking, scrolling, drumming and typing on a small keypad against screen $1^{5}$.

It has been reported in literature that females above age 40 are considered at high risk whereas other studies have reported both male and female at equal risk 16-18 of Extensor Carpi Radialis Brevis muscle and tendon trauma, because of the fact that these devices are built for convenience but not for optimal joint and muscles health. The condition is basically diagnosed by observation, history and examination.

Histopathologically, studies characterize this condition with over loading and is more frequent in dominant arm, especially in professional students where they use gadgets simultaneously with Smartphone use ${ }^{19}$ The ratio of reporting cases are increasing and side by side the usage is gaining momentum as it has become a fashion statement for all, though it does not meet ergonomical needs of postural satiability, IP is there to join a large list of young aged diseases as the condition is multi factorial. The aim of this study is not only to identify prevalence of IP in young students using Smartphone but also to create awareness in order to avoid health hazards. 


\section{METHODOLOGY}

The sample consists of 206 adolescent students of Doctor of Physical Therapy between 15-28 years of age. All students were invited to participate but only those who frequently use smart phones or handheld gadgets were included. The study was conducted in the college and the survey forms were equally distributed in all classes.

There were 206 participants for evaluation of percentage of Smartphone users who have developed or near to develop IP in their early age. A questionnaire was used contained questions related to the condition with mobile phone dependence in daily life. Participants were asked to mark their level of pain on Visual Analog Scale (VAS) to determine their level of difficulty, stage and severity of condition. COZEN test was also performed to confirm the diagnosis of IP.

\section{COZEN Test}

Cozen test was performed by stabilizing elbow in extension and palpating Lateral Epicondyle while other hand was used to resist wrist extension performed by participant. Test results are considered positive if participant complains of pain either localize that sustain for more than 30 seconds or radiating to forearm or burning sensation in the area of Lateral Epicondyle.

\section{Ethical Consideration}

The set of rules were adhered to the principles of the affirmation of college and has been approved by institutional review board. A written consent was obtained from each participant before each test performed. All participants had the right to withdraw from this study any time.

\section{Statistical Analysis}

The data was analyzed by using the SPSS version 20 . Cross tabulation was performed for the calculation of prevalence of IP with respect to age. Among all the activities participants executed on their Smartphone the most dominant factor that is causing lateral epicondylalgia is postural imbalance.

\section{RESULT}

The significant result is obtained due to the addition of Visual Analogues Scale (VAS) which was used to determine percentage of participants who developed Epicondylalgia ${ }^{20}$ and level of severity. Cozen test was performed to confirm the Epicondylitis. The final questionnaire consisted of mainly 6 sections and had high internal consistency. The information obtained was used to evaluate usage of Smartphone. Majority of students were users of smart phones for the past 3-5 years.

The corrected index for each of the item was up to 0.5; that is, the correlation between each of the activity and the time spent on Smartphone was marked 1 to 5 , indicating that all of the items measure the same construct, except VAS scale in which scores up to 10 is available. This technique was found to be helpful as it was assumed that all the factors in the sections and durations were interrelated with one another. Total Six factors were there for investigation.

Criteria used for evaluation under following research questions were:

\section{R1: Questions related to their demographic informa-} tion

- The first factor was age group ranges between 15-28 years and through this research we also came to know that the usage of Smartphone is more popular among 20 and 21 year old youngsters. As the frequency of both age group is 44 that is $21.4 \%$.

R2: Second part contains questions on activities they do on their Smartphone and time they spend on it:

To answer R2, participants were asked to mark multiple selections (Table 1) for types of usage which were presented in the related question and all the headings

\begin{tabular}{|c|c|}
\hline \multicolumn{2}{|l|}{ Table:1 } \\
\hline ACTIVITIES & $\%(2-4$ hours $)$ \\
\hline VOICE CALLS & 67.5 \\
\hline SENDING MESSAGE & 39.8 \\
\hline READING MESSAGE & 43.7 \\
\hline EMAIL & 57.8 \\
\hline TAKE PICTURES & 56.3 \\
\hline VIDEO CHAT & 60.7 \\
\hline $\begin{array}{l}\text { DOWNLOAD AND VIEW VIDEO } \\
\text { CLIPS }\end{array}$ & 52,4 \\
\hline MOBILE GAMING & 49.5 \\
\hline $\begin{array}{l}\text { DOWNLOAD AND LISTEN } \\
\text { MUSIC }\end{array}$ & 52.4 \\
\hline MOBILE SURFING & 48.0 \\
\hline BLUETOOTH & 55.8 \\
\hline MS OFFICE PROGRAM & 56.8 \\
\hline MOBILE TV & 53.9 \\
\hline INSTANT MESSENGER & 51.0 \\
\hline ENGAGING SOCIL NETWORKS & 40.3 \\
\hline PUTDOWN NOTES AND TASKS & 49.0 \\
\hline LEARN FROM PPT SLIDES & 47.6 \\
\hline
\end{tabular}


mentioned in the above table. Table 1 shows that majority of sample population spend at least 2-4 hours performing any of the mentioned tasks while holding their device in non neutral position.

- The trends in Smartphone usage is evaluated based on four categories namely (a) Education, (b) Communication, (c) Socializing and (d) Entertainment. These factor explained activities that user most frequently perform on Smartphone. It was composed of 11 items. Based on the content of those items following results were obtained although percentage of making calls and video chat is above $60 \%$ and percentage of reading message is $43.7 \%$ while sending message is $39.8 \%$ and putdown notes and task is $40 \%$ but comparing to talking in typing activity of muscles is high:

R3: Third part consists of questions that determine muscular strength and the region of pain:

- This study also asked participants about their level of pain that hinders their activity and the highest value obtained indicated that $33.3 \%$ participants sometimes feel pain whereas $10.3 \%$ often complain pain and uneasiness demonstrating that they have decreased muscular strength and have developed the epicondylalgia in elbow.

\begin{tabular}{|c|c|}
\hline \multicolumn{2}{|l|}{$\begin{array}{l}\text { Table:2 How do you experience weakness or } \\
\text { pain due to use of device? }\end{array}$} \\
\hline \\
\hline Never & $\mathbf{n ( \% )}$ \\
\hline rarely & $68(33.3)$ \\
\hline sometimes & $39(19.1)$ \\
\hline often & $72(35.3)$ \\
\hline always & $21(10.3)$ \\
\hline Total & $4(2.0)$ \\
\hline
\end{tabular}

R4: Forth part consist of questions on Posture they usually carry while using their device:
Table 3:

- The highest value obtained in this section indicated that there are $39.7 \%$ youngsters who most often use their device while sitting.

\begin{tabular}{|c|c|}
\hline \multicolumn{2}{|c|}{ How frequently do you hold mobile in sitting position? } \\
\hline & $\mathrm{n}(\%)$ \\
\hline never & $8(3.9)$ \\
\hline rarely & $19(9.3)$ \\
\hline sometimes & $35(17.2)$ \\
\hline often & $81(39.7)$ \\
\hline always & $61(29.9)$ \\
\hline Total & $\mathbf{2 0 4}$ \\
\hline
\end{tabular}

\section{Table 4:}

- The highest value obtained in this section indicated that there are $39.7 \%$ youngsters who often use supine lying posture while using their device.

\begin{tabular}{|c|c|}
\hline How frequently do you hold mobile in supline lying? \\
\hline & $\mathrm{n}(\%)$ \\
\hline never & $18(9.0)$ \\
\hline rarely & $25(12.4)$ \\
\hline sometimes & $49(24.4)$ \\
\hline often & $66(21.4)$ \\
\hline always & $43(21.4)$ \\
\hline Total & $\mathbf{2 0 4}$ \\
\hline
\end{tabular}

\section{Table 5:}

- The highest value obtained in this section indicated that there are $50 \%$ youngsters who never used smart phones in prone lying where as $27.9 \%$ rarely used their device in prone.

How frequently do you hold mobile in prone lying?

\begin{tabular}{|c|c|}
\hline & $\mathrm{n}(\%)$ \\
\hline never & $95(50.0)$ \\
\hline rarely & $53(27.9)$ \\
\hline sometimes & $28(14.7)$ \\
\hline often & $2(2.6)$ \\
\hline always & $9(4.7)$ \\
\hline Total & 190 \\
\hline
\end{tabular}


Table 6:

- The highest value obtained in this section indicated that there are $39.2 \%$ youngsters who sometimes use smart phone in side lying.

How frequently do you hold mobile in side lying?

\begin{tabular}{|c|c|}
\hline & $\mathrm{n}(\%)$ \\
\hline never & $33(17.01)$ \\
\hline rarely & $53(27.32)$ \\
\hline sometimes & $76(39.18)$ \\
\hline often & $19(9.79)$ \\
\hline always & $13(6.70)$ \\
\hline Total & 194 \\
\hline
\end{tabular}

Table 7:

- The highest value obtained in this section indicated that there are $46.1 \%$ youngsters who never use smart phone in side sitting where as $25.4 \%$ rarely use their device in side sitting.

How frequently do you hold mobile in side sitting?

\begin{tabular}{|c|c|}
\hline & $\mathrm{n}(\%)$ \\
\hline never & $89(46.1)$ \\
\hline rarely & $49(25.4)$ \\
\hline sometimes & $37(19.2)$ \\
\hline often & $8(4.1)$ \\
\hline always & $10(5.2)$ \\
\hline Total & 193 \\
\hline
\end{tabular}

\section{Table 8:}

- The highest value obtained in this section indicated that there are $48.5 \%$ youngsters who never use smart phone in half sitting whereas $17.0 \%$ rarely use their device in half sitting.

How frequently do you hold mobile in half sitting?

\begin{tabular}{|c|c|}
\hline & $\mathrm{n}(\%)$ \\
\hline never & $94(48.5)$ \\
\hline rarely & $33(17.0)$ \\
\hline sometimes & $34(17.5)$ \\
\hline often & $23(11.9)$ \\
\hline always & $10(5.2)$ \\
\hline Total & 194 \\
\hline
\end{tabular}

R5: VAS scale was given to participants as a format to mark the level of difficulty they face: Table 9:

- This scale was used to measure subjective characteristics. When responding on VAS scale it was convenient for the participants to mark their level of pain.

Table 9: Mark intensity of your pain on VAS scale

\begin{tabular}{|c|c|}
\hline & $\mathrm{n}(\%)$ \\
\hline No pain & $26(12.8)$ \\
\hline 1 & $70(34.5)$ \\
\hline mild pain & $66(32.5)$ \\
\hline 3 & $13(6.4)$ \\
\hline Nagging Pain & $22(10.8)$ \\
\hline 5 & $1(0.5)$ \\
\hline Miserable Pain & $3(1.5)$ \\
\hline Intense Pain & $1(0.5)$ \\
\hline worse Pain & $1(0.5)$ \\
\hline Total & $\mathbf{2 0 3}$ \\
\hline
\end{tabular}

- The highest value obtained in this section indicated that there are $34.5 \%$ youngsters who had slight discomfort where as second highest value obtained is for mild pain indicating that there were $32.5 \%$ of the sample population who had annoying pain due to use of their device which means that they have developed epicondylalgia in a very early age.

R6: COZEN Test was performed to confirm whether they have developed the condition or not:

Table 10:

- There were $80.6 \%$ negative results and only $19.4 \%$ test results turned out to be positive. Indicating that the highest value of target population has not developed the condition yet.

\begin{tabular}{|c|c|}
\hline \multicolumn{2}{|c|}{ Table 10: COZEN TEST } \\
\hline & $\mathrm{n}(\%)$ \\
\hline Negative & $166(80.6)$ \\
\hline Positive & $40(19.4)$ \\
\hline Total & $\mathbf{2 0 6}$ \\
\hline
\end{tabular}




\section{DISCUSSION}

Smartphone is getting popular and its use has been dramatically increasing from past few years to perform tasks easily and is more popular between ages of 20 and 21 as the frequency in both age groups is 44 that are $21.4 \%$.

The different activities performed on portable device required variable amount of force to generate by muscles. Although participants spend more time on activities that only require the device to grip as compared to the task which require constant typing, pressing and dragging of fingers and thumb on the screen. Repetitive motions are the most important risk factor for musculature ${ }^{21,22}$.

The posture, participants usually carry while using Smartphone such as sitting, supine lying, side lying, half lying and prone lying also affect the activity of muscle. Posture and contact pressure is strongly related to each other because elbow extension, forearm pronation while keeping elbow under varus stress has significant increase in the contact pressure 23,24 .

Our result obtained in this study concludes relatively low incidence of lateral epicondylitis at young age but with high prevalence of epicondylalgia. In previous studies the highest prevalence of lateral epicondylitis has been reported among subjects aged 40 years or above and women were also considered to develop lateral epicondylitis.

The pathogenesis of condition remains unclear. It is assumed that the muscles which are over working under constant stress may generate micro traumas and may become foundation in initiation of diseases at the origin of common extensor tendon. Extensor Carpi Radialis Brevis is the deep muscle and it originates from anterior surface of lateral epicondyle and inserts on the base of third Meta Carpel bone. Its primary function is wrist extension and abduction because it has a considerable contact with lateral edge of capitulum. This anatomical position of muscle could be considered as a great risk factor for injury. Being the deepest muscle in forearm extensor compartment it rubs against bony surface during elbow motion. Tendons are made up of strong connective tissues and provide muscle to bone connection. Their ability to withstand high tensile force suggests that any pathology to tendon which occurs after keeping muscle under mechanical overload for sustained duration. In response to micro tears, repairing process begins naturally and in later stages formation of granulation tissue becomes the primary cause of inflammation.

Our result obtained through this observational study concludes relatively low incidence of lateral epicondylitis at the young age but high prevalence of epicondylalgia that is considered to be the most dominant risk factor representing micro trauma to muscle.

The diagnosis of IP is usually based on localized pain at the lateral epicondyle of elbow, tenderness on palpation, painful resisted or isometric extension or flexion of the wrist. In this study we used VAS scale to determine prevalence of epicondylalgia and Cozen test for definite diagnosis of lateral epicondylitis.

Results obtained on VAS scale in this study concluded that there are $70 \%$ youngsters who had slight discomfort and $66 \%$ of the sample population who experienced annoying pain therefore developing lateral epicondylalgia. Whereas COZEN Test came out negative in $80.6 \%$ and only $19.4 \%$ test results turned out positive in the age group of 20-24 years.

In this observational study, exposure to posture-related physical loads and repetitive movements of the elbow, frequencies of using smart phone and age group at risk were assessed by a questionnaire. Our study showed that IP (lateral epicondylalgia or lateral epicondylitis) is strappingly coupled with smart phone use demanding a combination of repetitive and forceful movement and eccentric contraction for hours and so on.

The outcome of our study suggests that modification of physical load factors and decreased use of Smartphone could significantly reduce the risk of IP in future. It is the right time to consider conduction of muscular strength training programs; stretching, exercise and counseling classes about Smartphone usage and its consequences. Postural education could reduce the risk of developing symptoms of IP.

Limitation of our study was age range that is between 15-28 years, Subjects using their device for less than 2 hours were excluded and only Smartphone users were entertained and approached to participate in our study. Our sample size was not sufficient to estimate accurately the prevalence of IP and samples only involved the students of Doctor of Physical Therapy which acted as limitation in data collection. The VAS scale and COZEN test were used to minimize the chances of information bias.

In summary, the high percentage of participants using Smartphone have developed epicondylalgia where as epicondylitis was found to be relatively uncommon in early ages but responses we received from participants through questionnaire indicates that if youngsters do not decrease or stop usage of hand held gadget for multitasking for long duration, it may push them hard to develop IP therefore early aging of muscle. Physical load 
factors and ergonomically incorrect posture will disturb the normal biomechanics ${ }^{25}$ therefore keeping wrist and elbow deviated from their correct angulations will become greater consequence to develop IP.

\section{CONCLUSION}

We found that the prevalence of epicondylitis is not high in young students but there is marked number of sample population that has developed epicondylalgia and decreased muscular strength of muscles namely the Extensor Carpi Radialis Brevis and Longus. The supinator, brachioradialis, triceps, supraspinatus, anconeus and extensor digitorum (4th and 5th fingers) can also refer pain to the lateral epicondyle indicating that they had lower muscular activity level and due to this reason, participants feel discomfort in holding their device in elbow flexed, wrist extended position. Therefore, keeping the forearm in non neutral position and continuous level of activity with the same frequency on their smart phones they are at high risk of developing IP (Epicondylitis) in early ages.

\section{REFERENCES}

[1] 25 Amazing facts about mobile phones [Internet]. [cited 2014]. Available from: http://www.spinfold.com/./25amazing-facts-about-mobile-phones

[2] Gorges M. 90 percent of young people wake up with their smart phones [internet]. [updated 2012, cited 2014]. Available from: http://www.ragan.com/Main/Articles/90_per$c e n t-o f-y \circ u n g$ $\mathrm{p}$ o e o ple_wake_up_with_their_smar_45989.aspx

[3] Verbrugge K, Stevens I, De Marez L. The role of an omnipresent pocket device: smartphone attendance and the role of user habits. Proceedings of Crises 'Creative Destruction' and the Global Power and Communication Orders; 2013 June 25-29; Dublin, Ireland. Belgium: UGent; 2013

[4] Chichester $\mathrm{H}$. iPhone elbow is the new tennis elbow [Internet]. [updated 2013, cited 2014]. Available from: http://vitalityphysicaltherapy. com / 2 / post / 2013 / 07 / iphone-elbow-is-the-new-tennis-elbow.html

[5] Shiri R, Jantura EV, Varonen H, Helivara M. Prevalence and determinants of lateral and medial epicondylitis. a population study. Am J Epidemiol. 2006;164(1 1):1065-1074.

[6] Assendelft W, Green S, Buchbinder R, Struijs P, Smidt N. Tennis elbow. Clin Evid. 2003; (11):1633-1644

[7] Cyriax JH. The pathology and treatment of tennis elbow. J Bone Joint Surg 1936;18:921-940

[8] Franke F. Ueber epicondylitis humeri. Deutsche Med Wchnschr 1910;36:13
[9] Goldie I. Epicondylitis lateralishumeri (epicondylalgia or tennis elbow): a pathological study. Acta Chir Scand Suppl. 1964;339:1-119

[10] Kraushaar BS, Nirschl RP. Tendinosis of the elbow: clinical features and findings of histological, immunohistochemical and electron microscopy studies. J Bone Joint Surg Am. 1999;81:259-278

[11] Cohen M, filho G R M. lateralepicondylitis of the elbow. Redcube. 2012;47(4):414-20.

[12] Benton J. Ergonomics-101 why your iphone or ipad maybe causing you pain [Internet]. [cited 2015]. Available from: https://ehssafetynewsamerica.com/2015/01/02/ergonomics-101-why-your-iphone-or-ipad-may-be-causi ng-you-pain-2/

[13] Korkki P. So many gadgets, so many aches [Internet]. [updated 2011, cited 2014]. Available from: http://www.nytimes.com/2011/09/11/jobs/1 lwork.html

[14] Bemhang AM. Dehner W. Fogarty C: Tennis elbow: A biomechanical approach. J Sports Med. 1974;2:235-258

[15] Jonson GW, Cadwallader K, Schefel SB, Epperly TD. Treatment of lateral epicondylitis. Am Fam Physician. 2007;76(6):834-838

[16] Patten RM. Overuse syndromes and injuries involving the elbow: MR imaging findings. Am J Roentqenol. 1995;164(5):1205-1211

[17] Gunal AT, Ozturk H. Local injection treatment for lateral epcondylitis. Clin Orthop Relat Res. 2002;(398):127-130

[18] Bisset L, Bellar E, Jull G, Brooks P, Darnell R, Vicenzino B. Mobilization with movement and exercise. corticosteroid injection or wait and see for tennis elbow: randomised trial. BMJ. 2006;333(7575):939

[19] Edwards GS, CalandruccioJ H. Autologous blood injections for refractory lateral epicondylitis. PubMed. 2003;28(2):272-278

[20] Waugh JE. Lateral Epicondylalgia or Epicondylitis. What's in a Name. J Orthop Sports PhysTher. 2005;35(4): 200-264

[21] Stasinopoulos, Johnson MI . Cyriax physiotherapy for tennis elbow/lateral epicondylitis. Sports Med. 2004;38(6): 675-677

[22] Chan D, Aldridge MJ, Maffulli $\mathrm{N}$ et al. Chronic stress injuries of the elbow in young gymnasts. $\mathrm{Br}$ J Radiol. 1991;64(768):1113-1118

[23] Mayo Clinic Staff. Tennis elbow [Internet]. [updated 2013, cited 2014]. Availble from: http://www.mayoclinic.org/diseases-conditions/tennis-elbow/home/ovc-2020601 1

[24] Ezoe S, Toda M. Relationships of loneliness and mobile phone dependence with internet addiction in Japanese medical students. Open J Prev Med. 2013;3(6):407-412

[25] Ergonomics: upper body risk factor [internet]. [cited 2014]. Avaiable from: https://www.apple.com/about/ergonomics/uprsk.html 